\title{
Neurological outcome after extracorporeal cardiopulmonary resuscitation for in- hospital cardiac arrest: a systematic review and meta-analysis
}

Benjamin Yaël Gravesteijn ${ }^{1,2^{*}}$ (D), Marc Schluep ${ }^{1,3}$, Maksud Disli ${ }^{4}$, Prakriti Garkhail ${ }^{4}$, Dinis Dos Reis Miranda ${ }^{5}$, Robert-Jan Stolker ${ }^{1}$, Henrik Endeman ${ }^{5}$ and Sanne Elisabeth Hoeks ${ }^{1}$

\begin{abstract}
Background: In-hospital cardiac arrest (IHCA) is a major adverse event with a high mortality rate if not treated appropriately. Extracorporeal cardiopulmonary resuscitation (ECPR), as adjunct to conventional cardiopulmonary resuscitation (CCPR), is a promising technique for IHCA treatment. Evidence pertaining to neurological outcomes after ECPR is still scarce.

Methods: We performed a comprehensive systematic search of all studies up to December 20, 2019. Our primary outcome was neurological outcome after ECPR at any moment after hospital discharge, defined by the Cerebral Performance Category (CPC) score. A score of 1 or 2 was defined as favourable outcome. Our secondary outcome was post-discharge mortality. A fixed-effects meta-analysis was performed.

Results: Our search yielded 1215 results, of which 19 studies were included in this systematic review. The average survival rate was $30 \%\left(95 \% \mathrm{Cl} 28-33 \%, P^{2}=0 \%, p=0.24\right)$. In the surviving patients, the pooled percentage of favourable neurological outcome was $84 \%\left(95 \% \mathrm{Cl} 80-88 \%, l^{2}=24 \%, p=0.90\right)$.

Conclusion: ECPR as treatment for in-hospital cardiac arrest is associated with a large proportion of patients with good neurological outcome. The large proportion of favourable outcome could potentially be explained by the selection of patients for treatment using ECPR. Moreover, survival is higher than described in the conventional CPR literature. As indications for ECPR might extend to older or more fragile patient populations in the future, research should focus on increasing survival, while maintaining optimal neurological outcome.
\end{abstract}

Keywords: In-hospital cardiac arrest, ECPR, Neurological outcome, Brain injury, CPC, Cerebral performance category

\footnotetext{
* Correspondence: b.gravesteijn@erasmusmc.n!

'Department of Anaesthesiology, Erasmus University Medical Centre,

Rotterdam, The Netherlands

${ }^{2}$ Department of Public Health, Erasmus University Medical Centre, Rotterdam,

The Netherlands

Full list of author information is available at the end of the article
}

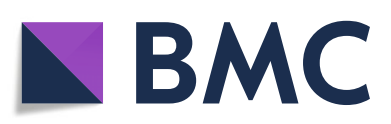

(- The Author(s). 2020 Open Access This article is licensed under a Creative Commons Attribution 4.0 International License, which permits use, sharing, adaptation, distribution and reproduction in any medium or format, as long as you give appropriate credit to the original author(s) and the source, provide a link to the Creative Commons licence, and indicate if changes were made. The images or other third party material in this article are included in the article's Creative Commons licence, unless indicated otherwise in a credit line to the material. If material is not included in the article's Creative Commons licence and your intended use is not permitted by statutory regulation or exceeds the permitted use, you will need to obtain permission directly from the copyright holder. To view a copy of this licence, visit http://creativecommons.org/licenses/by/4.0/. The Creative Commons Public Domain Dedication waiver (http://creativecommons.org/publicdomain/zero/1.0/) applies to the data made available in this article, unless otherwise stated in a credit line to the data. 


\section{Introduction}

In-hospital cardiac arrest (IHCA) is a serious adverse event in hospitalized patients that inevitably leads to death if not treated appropriately. It is associated with low survival rates at discharge and at 1-year follow-up (13\%, 95\% prediction interval 6-29\%) [1, 2]. The use of extracorporeal membrane oxygenation (ECMO) in addition to chest compressions for cardiopulmonary resuscitation may improve survival after IHCA [3]. Recent guidelines state the use of ECMO for CPR (ECPR) as potentially beneficial for specific patient populations [4]; however, they also stress the lack of evidence for this novel technique [5]. To our knowledge, there is no large-scale evidence pertaining to neurologic outcomes after ECPR for IHCA [6, 7].

Survivors of cardiac arrest also suffer from neurological sequelae, which have been described as the postcardiac arrest syndrome [8]. An important measure for neurological outcome is the aforementioned CPC. Although the CPC scoring suffers from limited discriminatory capacity and has a potential ceiling effect and possible overestimation of function, it is to date the most used outcome measure [9]. The neurological outcome of 1-year survivors after conventional CPR (CCPR) tends to be high: $92 \%$ of patients score a cerebral performance category (CPC) of 1 or 2 (95\% prediction interval 8297\%) [2]. Another important neurological score is the Glasgow Outcome Scale (GOS). This outcome scale was developed for scoring outcome after acquired brain injury, but also is used to assess functional outcome after cardiac arrest $[10,11]$.

ECPR facilitates return of circulation, albeit artificial. However, it is much more uncertain whether this recovery of circulation translates into survival, or acceptable neurological outcome. Furthermore, the association between neurologic outcomes and prognostic factors should be elicited, in particular time to ECMO [12]. This systematic review aims to summarize the evidence on neurologic outcomes after hospital discharge of patients treated with ECPR for in-hospital cardiac arrest.

\section{Methods}

\section{Literature search and selection criteria}

This systematic review and meta-analysis is reported following the PRISMA and MOOSE guidelines for reporting of systematic reviews and meta-analyses of observational studies $[13,14]$. For this systematic review, we performed a systematic search of all published data on post-discharge neurological outcome after IHCA treated by ECPR up to December 20, 2019. We used the search engines PubMed, EMBASE, Medline Ovid, Web of Science and Cochrane Central. Our searches contained the following keywords: in-hospital cardiac arrest, ECMO, neurological outcome, brain injury and neurological outcome. The exact search strategies are included in Additional file 1: Appendix 1.
Our inclusion criteria were as follows: (1) use of ECPR for in-hospital cardiac arrest, (2) adult patients, (3) reporting of neurological outcome (CPC or GOS), (4) clinical studies, and (5) written in English, German, French or Dutch. We included studies that reported outcome upon or after discharge from hospital. Studies were excluded if they did not fit inclusion criteria or if they were only published as abstract.

After the initial screening, the remaining articles were assessed by reading the full text. Studies often reported characteristics and outcomes of in-hospital and out-ofhospital cardiac arrest simultaneously. The authors of articles in which data for the IHCA cohort was not reported separately were contacted. Data extraction from selected studies was performed independently by two investigators (MD, PG) using a standardized form. Subsequently, the discrepancies were resolved by discussion with the other authors (BG, MS, SH).

\section{Definitions}

The primary outcome was defined as favourable neurological outcome post-discharge from hospital using CPC or GOS score. A measurement was considered postdischarge, when the outcome was reported at discharge or later. For a description of the CPC and the GOS score, see Table 1 and Additional file 2: Appendix 2. A CPC score of 1 or 2 or a GOS score of 4 or 5 was defined as favourable outcome. The secondary outcome was post-discharge survival. If a study reported survival and neurological outcome at different follow-up moments, we ensured extracting the data for the same follow-up moment per study. Additionally, out of interest in the time to ECMO cannulation on the effect of ECPR, we extracted the average time to ECMO per study. Only the effect of the average time to ECMO cannulation on the primary outcome (favourable outcome) was investigated.

\section{Quality assessment}

The quality of the included studies was evaluated using the method of Hayden et al. for prognosis studies in systematic reviews [15]. The quality assessment is based on six categories: (1) study population: whether the study correctly defines and describes the study population; (2) study attrition: whether the study was able to obtain a complete follow-up; (3) prognostic factor measurement: whether the study reports the most important prognostic characteristics; (4) outcome measurement: whether the neurological outcome was measured in a valid and robust way; (5) confounding measurement: whether the authors explored what influenced neurological outcome; and (5) account and analysis: whether the study reports a correct methodology of statistical analysis. Up to 2 points can be scored in each category. Therefore, the maximum score was 12 points, indicating high quality. 
Table 1 Overview and characteristics of the included studies

\begin{tabular}{|c|c|c|c|c|c|c|c|}
\hline Authors & $\begin{array}{l}\text { Year and journal } \\
\text { of publication }\end{array}$ & Study timeframe & Study type & Country & $\begin{array}{l}\text { ECPR age } \\
\text { median }\end{array}$ & $\begin{array}{l}\text { Cardiac arrest to } \\
\text { ECMO time (range) }\end{array}$ & $\begin{array}{l}\text { Time of CPC } \\
\text { assessment* }\end{array}$ \\
\hline Avalli et al. & Resuscitation. 2012 & $\begin{array}{l}\text { Jan } 2006 \text { to } \\
\text { Feb } 2011\end{array}$ & Retrospective & Italy & $67(61-73)$ & $55(40-70)$ & 6 months \\
\hline Bednarcyzk et al & Resuscitation. 2014 & $\begin{array}{l}\text { Feb } 2008 \text { to } \\
\text { Sep } 2013\end{array}$ & Retrospective & Canada & - & $49 \pm 21$ & Discharge \\
\hline Blumenstein et al. & $\begin{array}{l}\text { Eur Heart J Acute } \\
\text { Cardiovasc Care. } 2016\end{array}$ & $\begin{array}{l}\text { Jan } 2009 \text { to } \\
\text { Jan } 2013\end{array}$ & Retrospective & Germany & $72(55-72.9)$ & $33.0(19.0-47.0)$ & $\begin{array}{l}\text { Discharge } \\
\text { (30d) }\end{array}$ \\
\hline Chen et al. & Lancet 2008 & $\begin{array}{l}\text { Jan } 2004 \text { to } \\
\text { Dec } 2006\end{array}$ & Prospective & Taiwan & $61.5(18-74)$ & $52.8 \pm 37.2$ & Discharge \\
\hline Dennis et al. & Int J Cardiol. 2017 & 2009-2016 & Retrospective & Australia & - & $40(30-55)$ & Discharge \\
\hline Ellouze et al. & Artificial Organs 2018 & $\begin{array}{l}\text { Jan } 2011 \text { to } \\
\text { Jan } 2015\end{array}$ & Retrospective & France & - & $60(45-89)$ & 6 months \\
\hline Fagnoul et al. & Resuscitation. 2013 & $\begin{array}{l}\operatorname{Jan} 2012 \text { to } \\
\operatorname{Jan} 2013\end{array}$ & Prospective & Belgium & - & $55(42-59.5)$ & $\begin{array}{l}\text { Discharge } \\
\text { from ICU }\end{array}$ \\
\hline Jung et al. & Clin Res Cardiol. 2016 & 2002-2013 & Retrospective & Germany & $66(56-78)$ & - & $\begin{array}{l}\text { Discharge } \\
\text { (30d) }\end{array}$ \\
\hline Lazzeri et al. & Acute Cardiac Care 2013 & $\begin{array}{l}\operatorname{Jan} 2007 \text { to } \\
\operatorname{Jan} 2012\end{array}$ & Prospective & Italy & $\begin{array}{l}54.8 \pm 9 \text { years } \\
(24-74)\end{array}$ & $51.9 \pm 24.8$ & Discharge \\
\hline Lee et al. & ann thorac surg. 2016 & $\begin{array}{l}\text { Jan } 2004 \text { to } \\
\text { Dec } 2013\end{array}$ & Prospective & S. Korea & - & - & Discharge \\
\hline Lin et al. & Resuscitation. 2010 & 2004-2006 & Prospective & Taiwan & $62.3(21-73)$ & $40(16-150)$ & Discharge \\
\hline Liu et al. & $\begin{array}{l}\text { Interac cardiovasc thorac } \\
\text { surg. } 2011\end{array}$ & $\begin{array}{l}\text { Jan } 2001 \text { to } \\
\text { Aug } 2010\end{array}$ & Prospective & Taiwan & $53(50-69)$ & - & Discharge \\
\hline Mazzeffi et al. & $\begin{array}{l}\text { J thorac cardiovasc } \\
\text { surg. } 2016\end{array}$ & $\begin{array}{l}\text { Jan } 2010 \text { to } \\
\text { Dec } 2015\end{array}$ & Prospective & USA & $\begin{array}{l}57 \pm 15 \\
(34-86)\end{array}$ & $31(15-52)$ & Discharge \\
\hline Peigh et al. & $\begin{array}{l}\text { J thorac cardiovasc } \\
\text { surg. } 2015\end{array}$ & $\begin{array}{l}\text { Jun } 2010 \text { to } \\
\text { Jul } 2014\end{array}$ & Retrospective & USA & $46 \pm 12$ & $54 \pm 30$ & $\begin{array}{l}\text { 4-6w after } \\
\text { discharge }\end{array}$ \\
\hline Pozzi et al. & Ann thorac surg. 2019 & $\begin{array}{l}\text { Jan } 2007 \text { to } \\
\text { Dec } 2016\end{array}$ & Prospective & France & $\begin{array}{l}46.2 \pm 13.5 \\
(18-76)\end{array}$ & $46.9 \pm 19.0$ & Discharge \\
\hline Shin et al. & Int J Cardiol. 2013 & $\begin{array}{l}\text { Jan } 2003 \text { to } \\
\text { Jun } 2009\end{array}$ & Retrospective & S. Korea & $59.9 \pm 15.3$ & 38.8 & 6 months \\
\hline Spangenberg et al & $\begin{array}{l}\text { Catheter Cardiovasc } \\
\text { Interv. } 2016\end{array}$ & $\begin{array}{l}\text { Jan } 2014 \text { to } \\
\text { Oct } 2015\end{array}$ & Retrospective & Germany & - & $42.9 \pm 28.6$ & Discharge \\
\hline Stub et al. & Resuscitation. 2015 & $\begin{array}{l}\text { Nov } 2010 \text { to } \\
\text { Jul } 2014\end{array}$ & Prospective & Australia & - & $56(40-85)$ & Discharge \\
\hline Wang et al. & Resuscitation. 2014 & $\begin{array}{l}\text { Jan } 2007 \text { to } \\
\text { Aug } 2012\end{array}$ & Retrospective & Taiwan & $55.7 \pm 15.1$ & $40(15-162)$ & Discharge \\
\hline
\end{tabular}

*Neurological outcome and mortality was extracted at this follow-up moment

\section{Statistical analysis}

For the analysis of the primary outcome, a fixed-effects model was used, because little heterogeneity was observed. Results of the meta-analyses are presented as pooled proportions with corresponding $95 \%$ confidence intervals (CI). Between-study heterogeneity was assessed using $I^{2}$ statistic and the DerSimonian-Laird estimator for $\tau^{2}$. Moreover, heterogeneity was analysed by assessing statistical significance based on Cochran's $Q$ statistic.

Furthermore, because of specific interest in the relationship between time to ECMO and outcome in these patients, a meta-regression analysis was performed. A random intercept meta-regression analysis (binomialnormal model) was used with favourable outcome as outcome. This model is appropriate for meta-regression of probabilities, since it avoids the bias that occurs when a normal-normal model would be used for logittransformed probabilities [16].

Finally, we considered multiple follow-up moments for our primary and secondary outcome. Therefore, a sensitivity analysis was performed for the studies that used the most frequently reported follow-up moment (i.e. at discharge).

All data was extracted into Microsoft Excel and then analysed in R (R Core Team (2013). R: A language and environment for statistical computing. $\mathrm{R}$ Foundation for Statistical Computing, Vienna, Austria). The packages used for the analysis were 'meta' and 'metafor', of 
which we used the 'metaprop', 'forest' and 'rma.glmm functions'.

\section{Results}

\section{Included articles}

Our search yielded 1215 results. Subsequently, 1130 articles were excluded by screening of title and abstract $(2$ because of a language different than Dutch, English, French or German). Full-text screening resulted in inclusion of 28 articles, of which 9 did not report characteristics and outcome of the IHCA cohort separately. For these articles, authors were contacted to provide this data for the IHCA cohort. None replied after multiple attempts; therefore, these studies were excluded. Finally, 19 articles were included [17-35] (Fig. 1).
The sample size ranged between 10 and 200 patients. The mean age ranged between 18 and 86 . All studies were observational studies, of which 10 (53\%) were retrospective (Table 1). All studies mentioned contra-indications. The most frequently reported contra-indications were CPR duration (58\%), advanced age (58\%), terminal cancer (84\%), previous severe or irreversible brain damage (63\%) and uncontrollable bleeding (63\%). These are summarized in Table 2.

Fifteen $(79 \%)$ of the included studies had a score of $\geq 9$ (out of 12) in the Hayden method for quality assessment (Table 3). Thirteen studies (68\%) did not sufficiently adjust for confounding bias, while 18 studies (95\%) reported important prognostic characteristics. Overall, high quality was observed for study participation (13 studies, $68 \%$, received maximum scores), study attrition

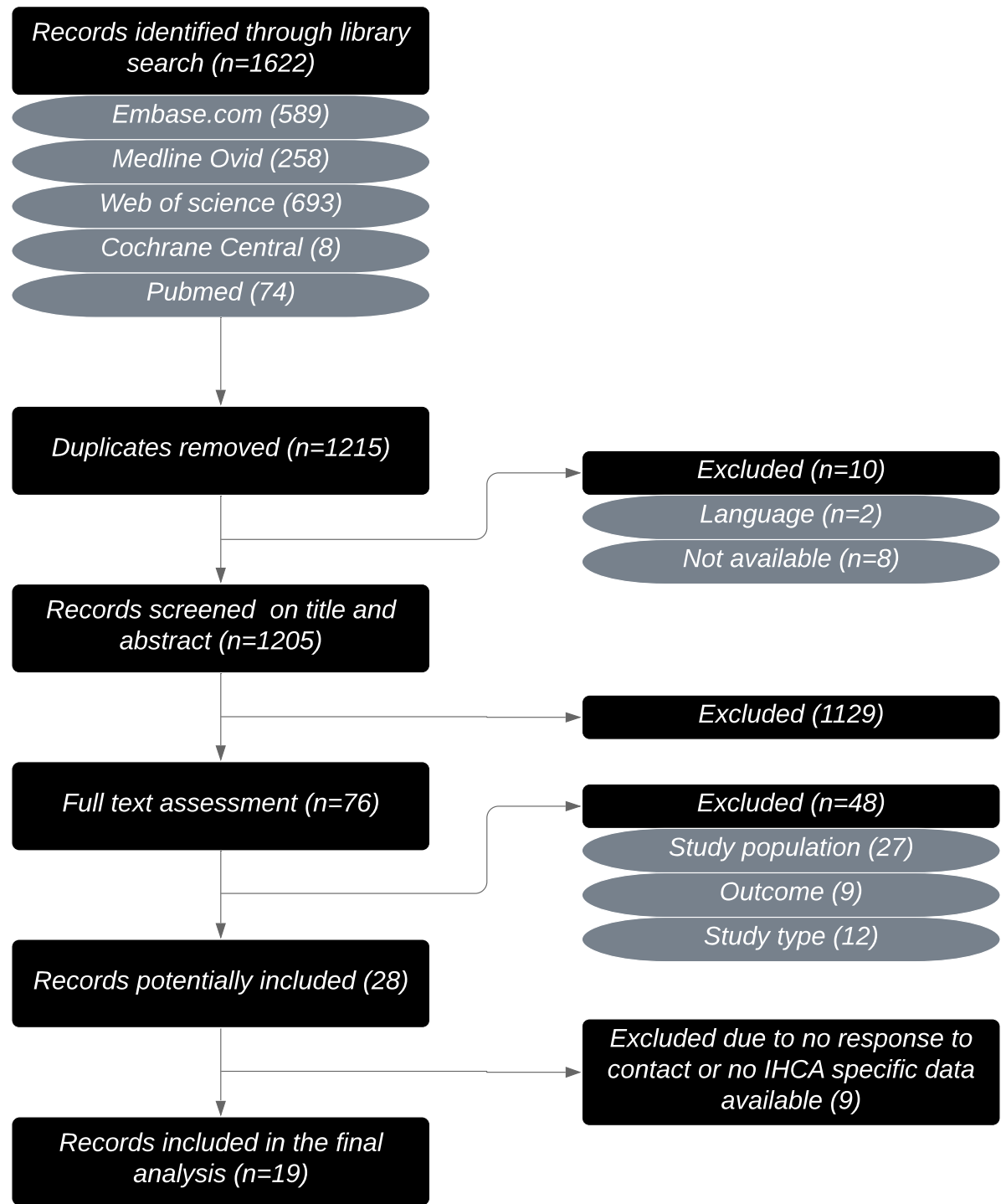

Fig. 1 Flowchart showing the process of inclusion of studies. The search strategy was performed on 20 December 2019 


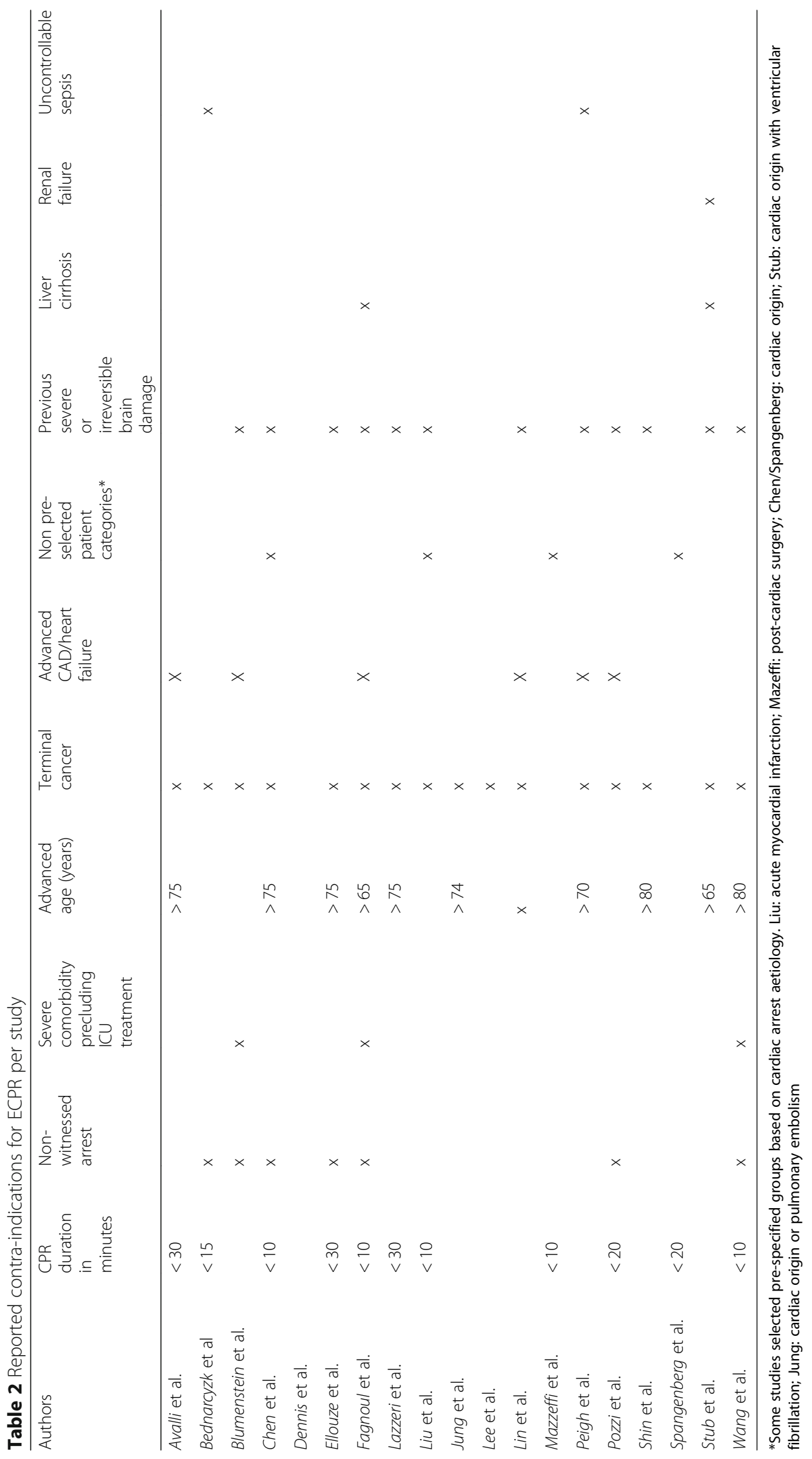




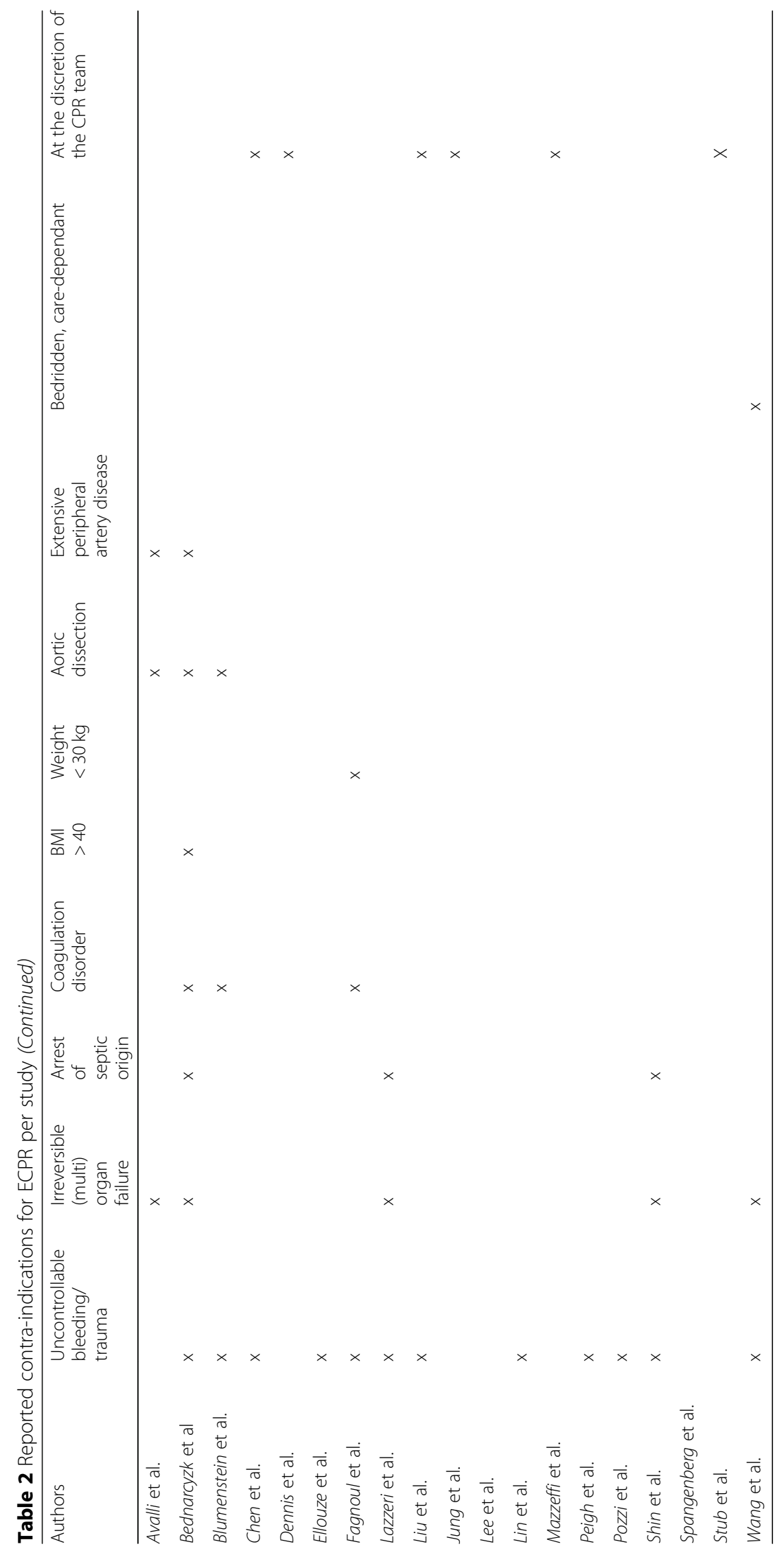


Table 3 Risk of bias assessment, using the method of Hayden et al. for prognosis studies in systematic reviews

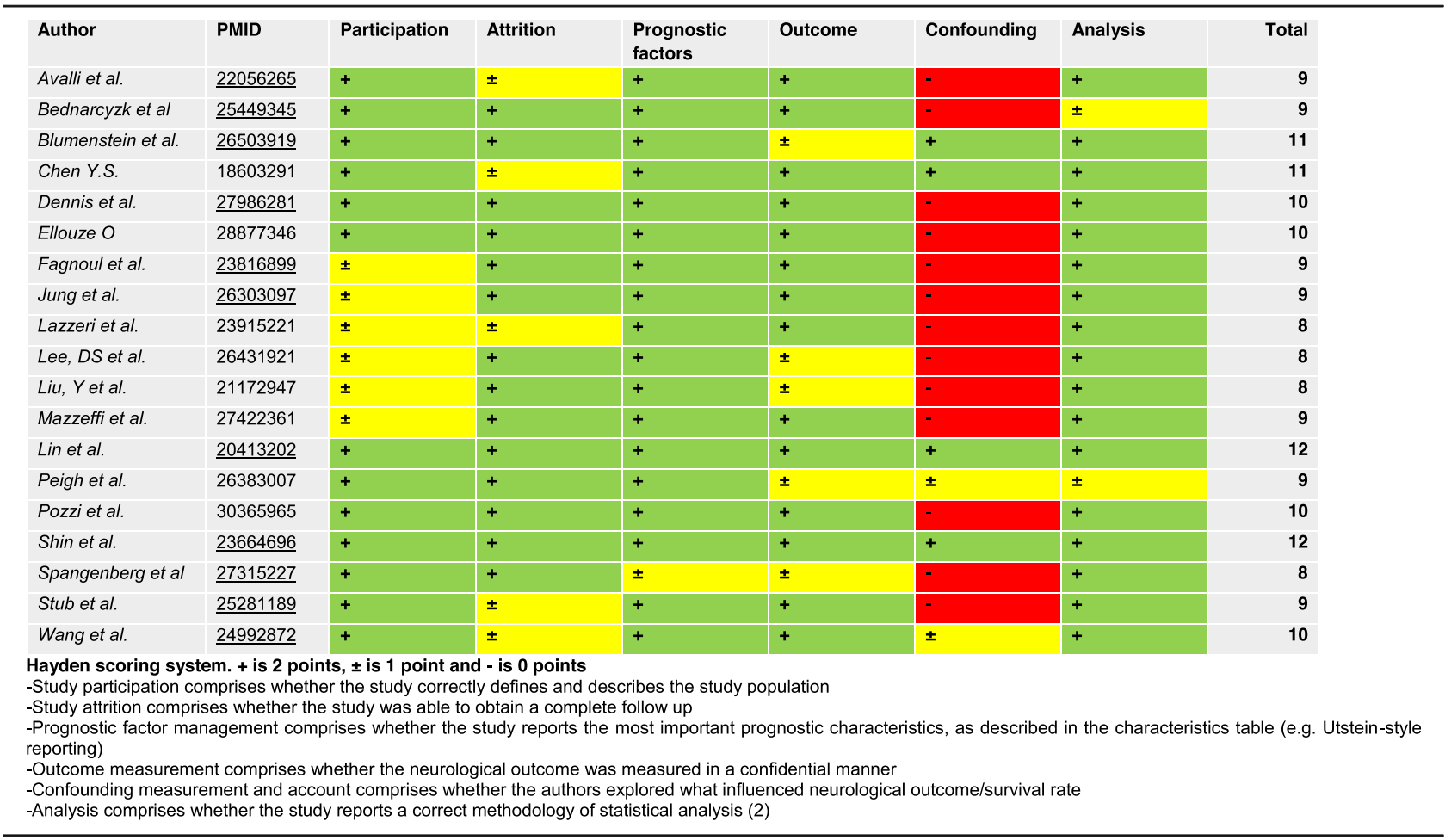

(14 studies, 74\%, received maximum scores), outcome measurement (14 studies, 74\%, received maximum scores) and analysis (17 studies, $89 \%$, received maximum scores).

None of the included articles expressed neurological outcome in GOS. Six studies showed that all survivors were classified as CPC 1-2 [17, 18, 24, 26, 30, 34]. The largest study reported 52 patients with CPC 1-2 (84\%) versus 10 patients with CPC 3-4 (16\%) [20]. There was variation in the timing of assessment of outcome: 15 studies (79\%) reported CPC and mortality at discharge, 2 (11\%) studies reported CPC and mortality at 6 months, 1 (5\%) study reported CPC and mortality at 4-6weeks after discharge and 1 (5\%) study reported CPC and mortality at discharge from ICU.

\section{Meta-analysis}

The average post-discharge survival rate (i.e. discharge until 6 months) was 30\% (95\% CI 28-33\%). Heterogeneity was low: $I^{2}=0 \%, p=0.24$. At the same follow-up moment in these survivors, the pooled proportion of favourable outcome was $84 \%$ (95\% CI 80-88\%). The heterogeneity was again low: $I^{2}=24 \%, p=0.90$ (Figs. 2 and 3).

As previously described, there was a variation in timing of assessment of outcome. In the 15 studies (79\%) which reported survival to discharge, the pooled survival rate was $30 \%$ (95\% CI $0.27-0.34 \%)$, with low heterogeneity $\left(I^{2}=0 \%, p=0.15\right)$. In these survivors, the pooled proportion of favourable neurological outcome was $83 \%$ (95\% CI 78-87\%), with again low heterogeneity $\left(I^{2}=0 \%, p=0.93\right)$.

\section{Meta-regression}

A total of 16 studies (84\%) reported an average time to ECMO (time to cannulation/time to start ECMO), and the reported range was large (31-60 $\mathrm{min})$. However, the OR per $10 \mathrm{~min}$ for favourable outcome was 1.29 (95\% CI 0.73-2.29): favourable outcome was not explained by the average time to ECMO per study.

\section{Discussion}

Our primary goal was to provide a comprehensive overview of current literature pertaining to neurological outcome after ECPR for in-hospital cardiac arrest. In post-discharge survivors, we found a high proportion of patients with a CPC 1-2 (84\% [95\% CI 80-88\%]), which is lower than described for 1-year survivors CCPR (92\% [95\% PI 82-97\%] [2]). Post-discharge survival was higher than reported for the general IHCA populations $(30 \%$ [95\% CI 28-33\%] versus $17 \%$ [95\% PI 13-23\%] [2, 36]). We found little heterogeneity in outcome between studies.

Although neurological outcome is good, it remains inconclusive whether neurological outcome of patients receiving ECPR is better than patients receiving CCPR. We did find a lower percentage of "good" neurological outcome $(\mathrm{CPC} 1-2)$ than in a systematic review in a 


\begin{tabular}{|c|c|c|c|c|c|c|c|}
\hline & Study & nts & Total & & & ortion & $95 \%-\mathrm{Cl}$ \\
\hline & Lazzeri 2013 & 2 & 4 & 1 & - & 0.50 & {$[0.01 ; 0.99]$} \\
\hline & Liu, Y 2011 & 3 & 3 & 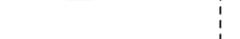 & 1 & 1.00 & {$[1.00 ; 1.00]$} \\
\hline & Pozzi 2019 & 3 & 5 & 1 & - & 0.60 & {$[0.17 ; 1.00]$} \\
\hline & Peigh 2015 & 7 & 7 & 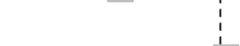 & 1 & 1.00 & {$[1.00 ; 1.00]$} \\
\hline & Mazzeffi 2016 & 6 & 7 & ! & - & 0.86 & {$[0.60 ; 1.00]$} \\
\hline & Chen Y.S. 2008 & 14 & 17 & 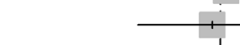 & - & 0.82 & {$[0.64 ; 1.00]$} \\
\hline & Ellouze O 2017 & 9 & 10 & $\begin{array}{l}1 \\
\end{array}$ & - & 0.90 & {$[0.71 ; 1.00]$} \\
\hline & Lee, DS 2016 & 52 & 62 & $\frac{1}{1}$ & & 0.84 & {$[0.75 ; 0.93]$} \\
\hline & Spangenberg 2016 & 6 & 6 & 1 & 1 & 1.00 & {$[1.00 ; 1.00]$} \\
\hline & Stub 2015 & 9 & 9 & tha & 1 & 1.00 & {$[1.00 ; 1.00]$} \\
\hline & Shin 2013 & 24 & 26 & $!$ & + & 0.92 & {$[0.82 ; 1.00]$} \\
\hline & Dennis 2017 & 9 & 9 & 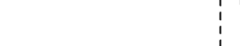 & 1 & 1.00 & {$[1.00 ; 1.00]$} \\
\hline & Avalli 2011 & 9 & 10 & \begin{tabular}{ll}
1 \\
\hdashline
\end{tabular} & $\square$ & 0.90 & {$[0.71 ; 1.00]$} \\
\hline & Lin 2010 & 13 & 16 & 4 & - & 0.81 & {$[0.62 ; 1.00]$} \\
\hline & Bednarcyzk 2014 & 15 & 15 & 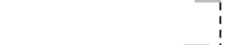 & 1 & 1.00 & {$[1.00 ; 1.00]$} \\
\hline & Blumenstein 2016 & 11 & 14 & $\begin{array}{l}1 \\
\end{array}$ & - & 0.79 & {$[0.57 ; 1.00]$} \\
\hline & Jung 2016 & 14 & 22 & $\longrightarrow$ & & 0.64 & {$[0.44 ; 0.84]$} \\
\hline & Wang 2014 & 50 & 62 & $+i$ & & 0.81 & {$[0.71 ; 0.90]$} \\
\hline & Fagnoul 2013 & 3 & 3 & & 1 & 1.00 & {$[1.00 ; 1.00]$} \\
\hline & Fixed effect model & & 307 & $\infty$ & & 0.84 & {$[0.80 ; 0.88]$} \\
\hline & Heterogeneity: $I^{2}=24 \%$ & $=0.1$ & $1610, p=0.90$ & \begin{tabular}{l|l|l} 
& 1
\end{tabular} & 7 & & \\
\hline & & & $\begin{array}{c}0.2 \\
\operatorname{PrC}\end{array}$ & $\begin{array}{ccc}0.4 & 0.6 & 0.8 \\
\text { bability } & \text { CPC } & 1 / 2\end{array}$ & 1 & & \\
\hline
\end{tabular}

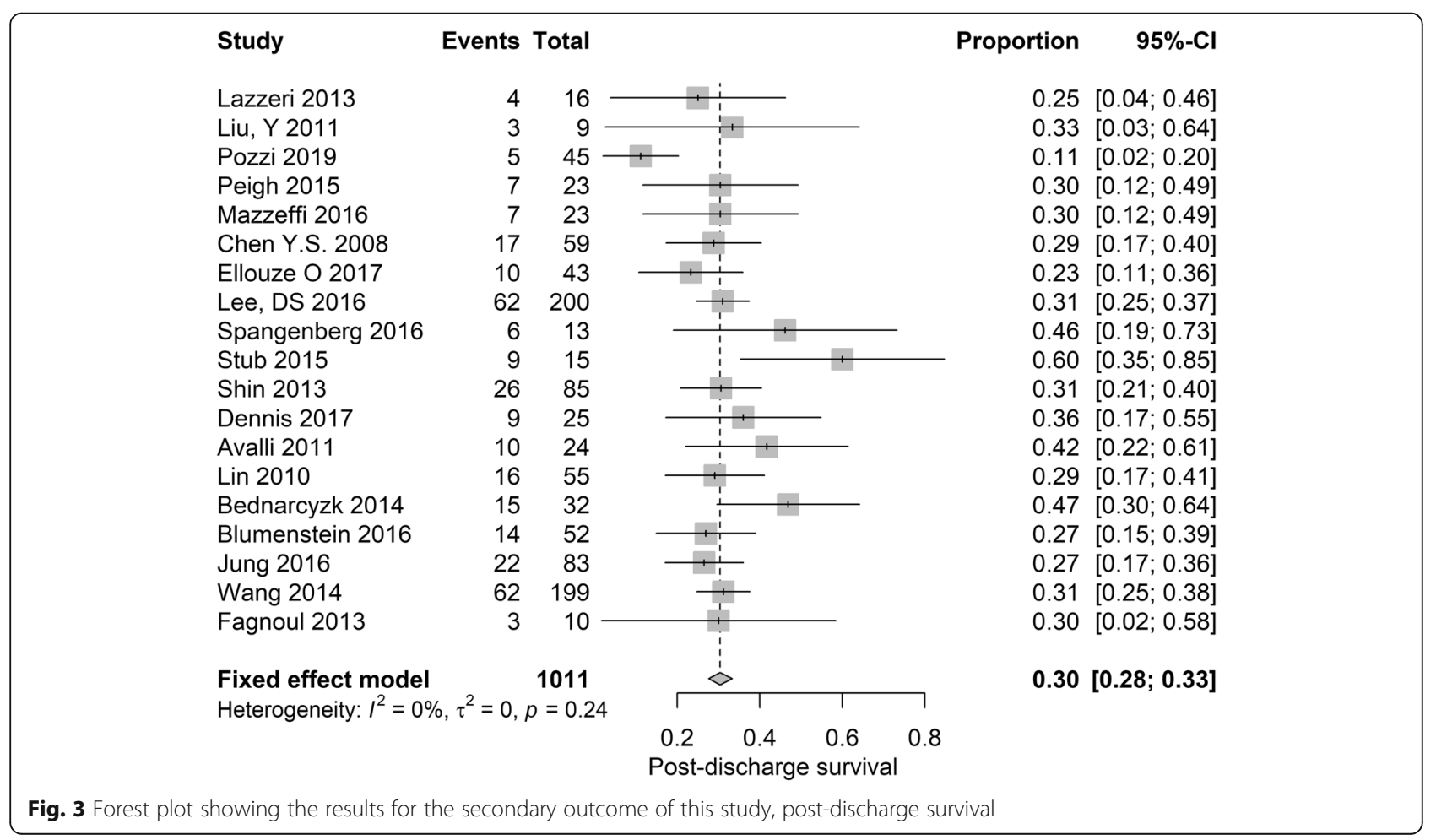


conventional CPR population [2]. However, in this review, CPC score was a secondary outcome. In this review, the proportion outcome assessment was also specifically set for 1 year, rather than after hospital discharge. A systematic review aimed at comparing ECPR and CCPR suggests that the neurological outcome is better in IHCA patients treated with ECPR compared to CCPR [37]. Due to the observational nature of the studies included in these reviews, the selection of patients for ECPR could still lead to better outcomes for this group. For literature pertaining to OHCA, the same caveats apply $[38,39]$.

Comparing this study to the literature suggests that survival of IHCA patients undergoing ECPR is higher than IHCA populations who receive conventional CPR (chest compressions) [1,2]. Our estimate of survival is also comparable the reported survival rate of adult ECPR patients by the ELSO registry [40]. This high survival might be explained by the selection of patients with a high chance of good outcome. The American Heart Association guidelines state that ECPR should be considered in patients for whom the suspected aetiology of the cardiac arrest is potentially reversible during a limited period of mechanical cardiorespiratory support [41]. In contrast, the European Resuscitation Council simply declares that the technique is a potential rescue therapy in patients where standard advanced life support (ALS) measures are not successful [5]. In practice, however, a much broader range of contraindications are being used: this study found that the primary reported contra-indications were CPR duration, age, severe comorbidities such as terminal cancer or pre-existing neurological impairments and uncontrolled bleeding. These contra-indications are known to impact prognosis. Excluding these patients from ECPR effectively results in a higher survival compared to patients receiving conventional CCPR. Especially the age criteria are quite stringent and therefore likely affect the apparent survival [42], given the average age of the CPR population [43]. Moreover, the finding that we found substantially less heterogeneity in survival rates between studies than a systematic review of the CCPR literature $[1,2]$ also supports the hypothesis that this is a selected population. Nevertheless, part of the difference might be explained by the effect of ECPR versus CCPR on outcome [44-46].

On the other hand, ECPR is only indicated in patients with refractory cardiac arrest. Therefore, patients eligible for ECPR have, by indication, a worse prognosis than patients with conventional CPR as a portion of these patients ROSC after a short resuscitation period [47]. As a result, ECPR patients might not be the patient population with the most favourable outcome.
Evidence in the literature suggests that a longer time to ECMO time is associated with lower benefit of ECPR [48-51]. Bartos et al. suggest the association between time to ECMO and survival is explained by the metabolic derangements, which develop during prolonged low-flow time, leading to a worse outcome [52]. In our meta-analysis, this association between time to ECMO and survival is not found. However, most of the studies included in our meta-analysis do find a relationship between time to ECMO and survival, when this was investigated [18, 22-27, 34]. Possibly, our results can be explained due to an aggregation effect: our results imply that-because the variation in outcome between studies was small-differences in mean calculated time to ECMO do not explain differences in mean survival between studies. Additionally, our results might be explained by the long time to ECMO in the included studies (> $30 \mathrm{~min}$ ). Given that the success rate of CPR is very low when the duration is longer than $30 \mathrm{~min}$ [53, 54], it might be more relevant to assess the effect of time to ECMO in when the time to ECMO is shorter. Since the effect of timing of ECPR on outcome impacts implementation, more high-quality evidence is needed.

Certain limitations should be taken into account. First, the time of CPC assessment was not the same for all studies. Most studies only scored CPC at the moment of discharge. This was not clearly defined in all studies. Some studies mentioned CPC scores at 6 months; others report a CPC score at discharge. We did show in a sensitivity analysis with the studies that reported data for the same follow-up moment that the estimates were very similar to the main analysis. However, a standardized and comprehensive assessment of neurologic and functional outcomes in cardiac arrest research is needed [9]. In spite of these differences, we encountered homogenous results, which suggest that the time of outcome assessment did not significantly influence the results: the neurological outcome and survival seem to remain constant at different follow-up times. Second, the included studies had two main shortcomings: they were relatively small (the largest study included 200 patients) and often reported their data non-standardized and nonstructured, which complicated the process of data extraction. Remarkably, we observed little heterogeneity between these small studies, which enabled us to perform a fixed-effects meta-analysis. Finally, we were not able to do an individual patient data meta-analysis. Since heterogeneity between studies was found, the effect of prognostic factors on outcome in these patients could not be explored effectively. An individual patient data metaanalysis would enable this [55] and could be of interest for future research.

By showing that treating a selected group of IHCA patients with ECPR can result in a high proportion of 
good neurological outcome, this study illustrates what next step the field should take. When centres become more experienced, the indications of ECPR will shift towards a less selected, but probably also more fragile patient population: older patients with more comorbidities might be considered eligible for ECPR in the near future. Nevertheless, we should focus on treating these patients while maintaining such a high proportion of favourable neurological outcome.

\section{Conclusion}

ECPR as treatment for in-hospital cardiac arrest is associated with a large proportion of patients with good neurological outcome (CPC 1-2). The large proportion of favourable outcome could potentially be explained by the selection of patients for treatment using ECPR. Nevertheless, both conventional and extracorporeal CPR are associated with low survival rates. The survival after ECPR, however, is higher than described in the conventional CPR literature. As indications for ECPR might extend to older or more fragile patient populations in the future, research should focus on increasing survival, while maintaining optimal neurological outcome.

\section{Supplementary information}

Supplementary information accompanies this paper at https://doi.org/10. 1186/s13054-020-03201-0.

Additional file 1: Appendix 1. Search strategy. Full search strategy, used in all databases.

Additional file 2: Appendix 2. Outcome measures. The definition of GOS and CPC scores, and the threshold for what is commonly defined as favourable outcome.

\section{Acknowledgements}

Not applicable.

\section{Authors' contributions}

BYG performed and interpreted the analysis, supervised the writing of the manuscript and revised the manuscript according to comments by the coauthors. MS was the initiator of the project, supervised the literature search and data extraction and supervised the writing of the manuscript. MD performed the literature search and data extraction and wrote the initial version of the manuscript. PG performed the literature search and data extraction and wrote the initial version of the manuscript. DDRM interpreted the results and helped writing the final manuscript. RJS provided the resources for this project, and helped writing the final manuscript. HE interpreted the results and helped writing the final manuscript. SEH interpreted the results and helped writing the final manuscript. The authors read and approved the final manuscript.

\section{Funding}

The authors received no funding for completing this work.

Availability of data and materials

Not applicable.

Ethics approval and consent to participate

Not applicable.

Consent for publication

Not applicable.

\section{Competing interests}

The authors declare to have no conflict of interest.

\section{Author details}

${ }^{1}$ Department of Anaesthesiology, Erasmus University Medical Centre, Rotterdam, The Netherlands. ${ }^{2}$ Department of Public Health, Erasmus University Medical Centre, Rotterdam, The Netherlands. ${ }^{3}$ Department of Intensive Care, OLVG, Amsterdam, The Netherlands. "Erasmus University Medical Centre School of Medicine, Rotterdam, The Netherlands.

${ }^{5}$ Department of Intensive Care Medicine, Erasmus University Medical Centre, Rotterdam, The Netherlands.

Received: 28 February 2020 Accepted: 26 July 2020

Published online: 17 August 2020

\section{References}

1. Zhu A, Zhang J. Meta-analysis of outcomes of the 2005 and 2010 cardiopulmonary resuscitation guidelines for adults with in-hospital cardiac arrest. Am J Emerg Med. 2016;34:1133-9 [cited 2018 Mar 22] Available from: http://linkinghub.elsevier.com/retrieve/pii/S073567571600190X.

2. Schluep M, Gravesteijn BY, Stolker RJ, Endeman H, Hoeks SE. One-year survival after in-hospital cardiac arrest: a systematic review and metaanalysis. Resuscitation. 2018;132:90-100 [cited 2018 Nov 15] Available from: http://www.ncbi.n/m.nih.gov/pubmed/30213495.

3. Chen YS, Chao A, Yu HY, Ko WJ, Wu H, Chen RJC, et al. Analysis and results of prolonged resuscitation in cardiac arrest patients rescued by extracorporeal membrane oxygenation. J Am Coll Cardiol. 2003;41: 197-203.

4. ELSO ECPR Supplement to the ELSO General Guidelines Extracorporeal Life Support Organization (ELSO) Guidelines for ECPR Cases. 2013.

5. Soar J, Nolan JP, Böttiger BW, Perkins GD, Lott C, Carli P, et al. European resuscitation council guidelines for resuscitation 2015. Section 3. Adult advanced life support. Resuscitation. 2015;95:100-47.

6. Wang J, Ma Q, Zhang H, Liu S, Zheng Y. Predictors of survival and neurologic outcome for adults with extracorporeal cardiopulmonary resuscitation: a systemic review and meta-analysis. Med. (United States). Lippincott Williams and Wilkins; 2018.

7. Z. C, C. L, J. H, P. Z, J. L, R. Z, et al. Clinical efficacy of extracorporeal cardiopulmonary resuscitation for adults with cardiac arrest: meta-analysis with trial sequential analysis. Biomed Res Int. L. Zuo, Intensive Care Unit, Shunde Hospital, Southern Medical University, First People's Hospital of Shunde, Foshan, Guangdong Province, China; 2019;2019. Available from: http://www.embase.com/search/results?subaction=viewrecord\&from= export\&id=L628647783.

8. ACC/AHA, Neumar RW, Nolan JP, Adrie C, Aibiki M, Berg RA, et al. Postcardiac arrest syndrome: epidemiology, pathophysiology, treatment, and prognostication. A consensus statement from the International Liaison Committee on Resuscitation (American Heart Association, Australian and New Zealand Council on Resuscitation, . Circulation. 2008/10/25. 2008 [cited 2019 Nov 25];118:2452-83. Available from: http://www.ncbi.nlm.nih.gov/ pubmed/18948368.

9. Haywood K, Whitehead L, Nadkarni VM, Achana F, Beesems S, Böttiger BW, et al. COSCA (Core Outcome Set for Cardiac Arrest) in adults: an advisory statement from the International Liaison Committee on Resuscitation. Resuscitation. 2018;127:147-63 Available from: https://linkinghub.elsevier. com/retrieve/pii/S0300957218301321.

10. Jennett $B$, Bond M. Assessment of outcome after severe brain damage. Lancet. 1975;1:480-4.

11. Sivaraju A, Gilmore EJ, Wira CR, Stevens A, Rampal N, Moeller JJ, et al. Prognostication of post-cardiac arrest coma: early clinical and electroencephalographic predictors of outcome. Intensive Care Med Springer Verlag. 2015;41:1264-72.

12. Sandroni C, Nolan J, Cavallaro F, Antonelli M, Sandroni C, Cavallaro F, et al In-hospital cardiac arrest: incidence, prognosis and possible measures to improve survival. Intensive Care Med. 2007;33:237-45 [cited 2018 Mar 22] Available from: http://citeseerx.ist.psu.edu/viewdoc/download?doi= 10.1.1.524.1376\&rep=rep $1 \&$ type $=p d f$.

13. Moher D, Liberati A, Tetzlaff J, Altman DG. Preferred reporting items for systematic reviews and meta-analyses: the PRISMA statement. J Clin Epidemiol. 2009;62:1006-12. 
14. Stroup DF, Berlin JA, Morton SC, Olkin I, Williamson GD, Rennie D, et al. Meta-analysis of observational studies in epidemiology: a proposal for reporting. J Am Med Assoc. 2000;283:2008-12.

15. Hayden JA, Côté $P$, Bombardier C. Evaluation of the quality of prognosis studies in systematic reviews. Ann Intern Med. 2006;144:427 [cited 2019 Nov 25] Available from: http://annals.org/article.aspx?doi=10.7326/0003-481 9-144-6-200603210-00010.

16. Stijnen T, Hamza TH, Özdemir P. Random effects meta-analysis of event outcome in the framework of the generalized linear mixed model with applications in sparse data. Stat Med. 2010;29:3046-67.

17. Lazzeri C, Sori A, Bernardo P, Picariello C, Gensini GF, Valente S. In-hospital refractory cardiac arrest treated with extracorporeal membrane oxygenation: A tertiary single center experience. Acute Card Care. 2013;15:47-51 [cited 2019 Nov 25] Available from: http://www.tandfonline.com/doi/full/10.3109/1 7482941.2013.796385.

18. Pozzi M, Armoiry X, Achana F, Koffel C, Pavlakovic I, Lavigne F, et al. Extracorporeal life support for refractory cardiac arrest: a 10-year comparative analysis. Ann Thorac Surg. 2019;107:809-16 [cited 2019 Nov 25] Available from: https://linkinghub.elsevier.com/retrieve/pii/ S0003497518315182.

19. Peigh G, Cavarocchi N, Hirose H. Saving life and brain with extracorporeal cardiopulmonary resuscitation: a single-center analysis of in-hospital cardiac arrests. J Thorac Cardiovasc Surg. 2015;150:1344-9.

20. Liu Y, Cheng YT, Chang JC, Chao SF, Chang BS. Extracorporeal membrane oxygenation to support prolonged conventional cardiopulmonary resuscitation in adults with cardiac arrest from acute myocardial infarction at a very low-volume centre. Interact Cardiovasc Thorac Surg. 2011;12:38993 [cited 2019 Nov 25] Available from: https://academic.oup.com/icvts/ article-lookup/doi/10.1510/icvts.2010.256388.

21. Mazzeffi MA, Sanchez PG, Herr D, Krause E, Evans CF, Rector R, et al. Outcomes of extracorporeal cardiopulmonary resuscitation for refractory cardiac arrest in adult cardiac surgery patients. J Thorac Cardiovasc Surg. 2016;152:1133-9.

22. Lee DS, Chung CR, Jeon K, Park CM, Suh GY, Bin SY, et al. Survival after extracorporeal cardiopulmonary resuscitation on weekends in comparison with weekdays. Ann Thorac Surg. 2016;101:133-40.

23. Chen Y-S, Lin J-W, Yu H-Y, Ko W-J, Jerng J-S, Chang W-T, et al. Cardiopulmonary resuscitation with assisted extracorporeal life-support versus conventional cardiopulmonary resuscitation in adults with in-hospital cardiac arrest: an observational study and propensity analysis. Lancet. 2008; 372:554-61 [cited 2019 Nov 25] Available from: https://inkinghub.elsevier. com/retrieve/pii/S0140673608609587.

24. Ellouze O, Vuillet M, Perrot J, Grosjean S, Missaoui A, Aho S, et al. Comparable outcome of out-of-hospital cardiac arrest and in-hospital cardiac arrest treated with extracorporeal life support. Artif Organs. 2018;42: 15-21 [cited 2019 Nov 25] Available from: http://doi.wiley.com/10.1111/ aor.12992.

25. Spangenberg T, Meincke F, Brooks S, Frerker C, Kreidel F, Thielsen T, et al. "Shock and Go?" extracorporeal cardio-pulmonary resuscitation in the golden-hour of ROSC. Catheter Cardiovasc Interv. 2016;88:691-6 [cited 2019 Nov 25] Available from: http://doi.wiley.com/10.1002/ccd.26616.

26. Stub D, Bernard S, Pellegrino V, Smith K, Walker T, Sheldrake J, et al. Refractory cardiac arrest treated with mechanical CPR, hypothermia, ECMO and early reperfusion (the CHEER trial). Resuscitation. 2015;86:88-94.

27. Shin TG, Jo IJ, Sim MS, Song YB, Yang JH, Hahn JY, et al. Two-year survival and neurological outcome of in-hospital cardiac arrest patients rescued by extracorporeal cardiopulmonary resuscitation. Int J Cardiol. 2013;168:3424-30.

28. Dennis M, McCanny P, D'Souza M, Forrest P, Burns B, Lowe DA, et al. Extracorporeal cardiopulmonary resuscitation for refractory cardiac arrest: a multicentre experience. Int J Cardiol. 2017;231:131-6.

29. Avalli L, Maggioni E, Formica F, Redaelli G, Migliari M, Scanziani M, et al. Favourable survival of in-hospital compared to out-of-hospital refractory cardiac arrest patients treated with extracorporeal membrane oxygenation: an Italian tertiary care Centre experience. Resuscitation. 2012;83:579-83.

30. Lin JW, Wang MJ, Yu HY, Wang CH, Chang WT, Jerng JS, et al. Comparing the survival between extracorporeal rescue and conventional resuscitation in adult in-hospital cardiac arrests: propensity analysis of three-year data. Resuscitation. 2010;81:796-803.

31. Bednarczyk JM, White CW, Ducas RA, Golian M, Nepomuceno R, Hiebert B, et al. Resuscitative extracorporeal membrane oxygenation for in hospital cardiac arrest: a Canadian observational experience. Resuscitation. 2014;85:1713-9.
32. Blumenstein J, Leick J, Liebetrau C, Kempfert J, Gaede L, Groß S, et al. Extracorporeal life support in cardiovascular patients with observed refractory in-hospital cardiac arrest is associated with favourable short and long-term outcomes: a propensity-matched analysis. Eur Hear J Acute Cardiovasc Care. 2016;5:13-22.

33. Jung C, Janssen K, Kaluza M, Fuernau G, Poerner TC, Fritzenwanger M, et al. Outcome predictors in cardiopulmonary resuscitation facilitated by extracorporeal membrane oxygenation. Clin Res Cardiol. 2016;105:196-205.

34. Wang CH, Chou NK, Becker LB, Lin JW, Yu HY, Chi NH, et al. Improved outcome of extracorporeal cardiopulmonary resuscitation for out-of-hospital cardiac arrest - a comparison with that for extracorporeal rescue for inhospital cardiac arrest. Resuscitation. 2014;85:1219-24.

35. Fagnoul D, Taccone FS, Belhaj A, Rondelet B, Argacha JF, Vincent JL, et al. Extracorporeal life support associated with hypothermia and normoxemia in refractory cardiac arrest. Resuscitation. 2013;84:1519-24 Available from: http://www.embase.com/search/results?subaction=viewrecord\&from= export\&id=L52690128.

36. Zhu A, Zhang J. Meta-analysis of outcomes of the 2005 and 2010 cardiopulmonary resuscitation guidelines for adults with in-hospital cardiac arrest. Am J Emerg Med. J. Zhang. 2016;34:1133-9 Available from: http://www.embase. com/search/results?subaction=viewrecord\&from=export\&id=L610622958.

37. Chen Z, Liu C, Huang J, Zeng P, Lin J, Zhu R, et al. Clinical efficacy of extracorporeal cardiopulmonary resuscitation for adults with cardiac arrest: Meta-analysis with trial sequential analysis. Biomed Res. Int; 2019. Available from: https://www.hindawi.com/journals/bmri/2019/6414673/.

38. Holmberg MJ, Geri G, Wiberg S, Guerguerian A-M, Donnino MW, Nolan JP, et al. Extracorporeal cardiopulmonary resuscitation for cardiac arrest: a systematic review. Resuscitation. 2018;131:91-100 [cited 2018 Dec 5] Available from: http://www.ncbi.n/m.nih.gov/pubmed/30063963.

39. Beyea MM, Tillmann BW, lansavichene AE, Randhawa VK, Van Aarsen K, Nagpal AD. Neurologic outcomes after extracorporeal membrane oxygenation assisted CPR for resuscitation of out-of-hospital cardiac arrest patients: a systematic review. Resuscitation; 2018. p. 146-158.

40. Extracorporeal life support organisation. ECLS registry report [Internet]. 2019. Available from: https://www.elso.org/Registry/Statistics/ InternationalSummary.aspx.

41. Link MS, Berkow LC, Kudenchuk PJ, Halperin HR, Hess EP, Moitra VK, et al. Part 7: adult advanced cardiovascular life support: 2015 American Heart Association guidelines update for cardiopulmonary resuscitation and emergency cardiovascular care. Circulation. 2015;132:S444-64.

42. Bartos JA, Grunau B, Carlson C, Duval S, Ripeckyj A, Kalra R, et al. Improved survival with extracorporeal cardiopulmonary resuscitation despite progressive metabolic derangement associated with prolonged resuscitation. Intensive Care Med. 2019;45:44-54 [cited 2020 Jan 15] Available from: http://ahajournals.org.

43. Girotra S, Nallamothu BK, Spertus JA, Li Y, Krumholz HM, Chan PS. Trends in survival after in-hospital cardiac arrest. Circulation. 2011;124. Available from: http://www.embase.com/search/results?subaction=viewrecord\&from= export\&id=L70619607.

44. Ouweneel DM, Schotborgh JV, Limpens J, Sjauw KD, Engström AE, Lagrand WK, et al. Extracorporeal life support during cardiac arrest and cardiogenic shock: a systematic review and meta-analysis. Intensive Care Med. 2016;42: 1922-34 [cited 2018 Nov 15] Available from: http://link.springer.com/10.1 007/s00134-016-4536-8.

45. Tramm R, llic D, Davies AR, Pellegrino VA, Romero L, Hodgson C. Extracorporeal membrane oxygenation for critically ill adults. Cochrane Database Syst Rev. 2015;1:CD010381. Available from: https://doi.org/10.1002/ 14651858.CD010381.pub2.

46. Wang G-N, Chen X-F, Qiao L, Mei Y, Lv J-R, Huang X-H, et al. Comparison of extracorporeal and conventional cardiopulmonary resuscitation: a meta-analysis of 2260 patients with cardiac arrest. World J Emerg Med. The Second Affiliated Hospital of Zhejiang University School of Medicine; 2017 ;8:5-11. [cited 2018 Oct 1] Available from: http://www.ncbi.nlm.nih.gov/pubmed/28123613.

47. Gravesteijn BY, Schluep M, Voormolen DC, der Burgh AC, Miranda DDR, Hoeks Sanne E.and Endeman H. Cost-effectiveness of extracorporeal cardiopulmonary resuscitation afterin-hospital cardiac arrest: a Markov decision model. Resuscitation. ELSEVIER HOUSE, BROOKVALE PLAZA, EAST PARK SHANNON, CO, CLARE, 00000,IRELAND: ELSEVIER IRELAND LTD; 2019;143:150-157.

48. Twohig CJ, Singer B, Grier G, Finney SJ. A systematic literature review and meta-analysis of the effectiveness of extracorporeal-CPR versus conventional-CPR for adult patients in cardiac arrest. JICS. 2019;20(5):347-57. 
49. Otani T, Sawano H, Natsukawa T, Nakashima T, Oku H, Gon C, et al. Lowflow time is associated with a favorable neurological outcome in out-ofhospital cardiac arrest patients resuscitated with extracorporeal cardiopulmonary resuscitation. J Crit Care WB Saunders. 2018:48:15-20.

50. Ryu J-A, Chung CR, Cho YH, Kiick S, and Jeon K, Suh GY, et al. Neurologic outcomes in patients who undergo extracorporeal cardiopulmonary resuscitation. Ann Thorac Surg. STE 800, 230 PARK AVE, NEW YORK, NY 10169 USA: ELSEVIER SCIENCE INC; 2019;108:749-55.

51. Yu H-Y, Wang C-H, Chi N-H, Huang S-C, Chou H-W, Chou N-K, et al. Effect of interplay between age and low-flow duration on neurologic outcomes of extracorporeal cardiopulmonary resuscitation. Intensive Care Med. 2019;45: 44-54 [cited 2020 Jan 26] Available from: http://link.springer.com/10.1007/ s00134-018-5496-y.

52. Bartos JA, Grunau B, Carlson C, Duval S, Ripeckyj A, Kalra R, et al. Improved survival with extracorporeal cardiopulmonary resuscitation despite progressive metabolic derangement associated with prolonged resuscitation. Circulation. 2020 [cited 2020 Jan 26]; Available from: http:// www.ncbi.nlm.nih.gov/pubmed/31896278.

53. Rohlin O, Taeri T, Netzereab S, Ullemark E, Djärv T. Duration of CPR and impact on 30-day survival after ROSC for in-hospital cardiac arrest-a Swedish cohort study. Resuscitation. 2018;132:1-5.

54. Funada A, Goto Y, Tada H, Teramoto R, Shimojima M, Hayashi K, et al. Duration of cardiopulmonary resuscitation in patients without prehospital return of spontaneous circulation after out-of-hospital cardiac arrest: results from a severity stratification analysis. Resuscitation. 2018;124:69-75.

55. Riley RD, Lambert PC, Abo-Zaid G. Meta-analysis of individual participant data: rationale, conduct, and reporting. BMJ. 2010;340:521-5.

\section{Publisher's Note}

Springer Nature remains neutral with regard to jurisdictional claims in published maps and institutional affiliations.

Ready to submit your research? Choose BMC and benefit from:

- fast, convenient online submission

- thorough peer review by experienced researchers in your field

- rapid publication on acceptance

- support for research data, including large and complex data types

- gold Open Access which fosters wider collaboration and increased citations

- maximum visibility for your research: over $100 \mathrm{M}$ website views per year

At $\mathrm{BMC}$, research is always in progress.

Learn more biomedcentral.com/submissions 